\title{
INCIDÊNCIA DE ERVAS DANINHAS E ATRIBUTOS DO SOLO EM UM AGROSSISTEMA DA PRÉ-AMAZÔNIA, SOB EFEITO DA COBERTURA MORTA DE DIFERENTES COMBINAÇÕES DE LEGUMINOSAS EM ALÉIAS
}

\section{INFLUENCE OF SOIL COVER OF DIFERENT LEGUME COMBINATIONS ON WEED INFESTATION AND SOIL QUALITY IN A PRE-AMAZONIAN ALLEY- CROPPING AGROSYSTEM}

\author{
Emanoel Gomes de MOURA ${ }^{1}$ \\ Alana das Chagas Ferreira AGUIAR ${ }^{2}$ \\ Altamiro Souza de Lima FERRAZ JUNIOR ${ }^{3}$ \\ Marlon Gomes da COSTA 4 \\ João Thiago Rodrigues de SOUSA ${ }^{5}$ \\ Edílson Máximo da SILVA JUNIOR ${ }^{6}$ \\ Christoph GEHRING
}

\begin{abstract}
RESUMO
Nos agrossistemas do trópico úmido a variedade e a agressividade das ervas daninhas, são muito grandes, o que dificulta a adoção do plantio direto. Este trabalho foi conduzido com o objetivo de avaliar o efeito de resíduos resultante de diferentes combinações de leguminosas em aléias, sobre a densidade e biomassa de ervas daninhas e alguns atributos do solo. O experimento foi instalado em janeiro de 2002 no campus da Universidade Estadual do Maranhão (UEMA), com as leguminosas: Leucaena leucocephala (Lam.) De Wit.) (leucena), Cajanus cajan (L.) Millsp) (guandu), Clitoria fairchildiana R.A.Howard (sombreiro) e Acacia mangium Willd. (acácia), formando os tratamentos: Sombreiro + Guandu; Leucena + Guandu; Acácia + Guandu; Sombreiro + Leucena; Leucena + Acácia e Testemunha. Utilizou-se o delineamento experimental em blocos ao acaso, com quatro repetições. As amostragens foram realizadas em 2005 e 2007 . Foram determinados os teores de N, P, K, Ca, lignina e polifenol nos resíduos, o pH, matéria orgânica, $\mathrm{P}, \mathrm{K}, \mathrm{Ca}, \mathrm{Mg}, \mathrm{H}+\mathrm{Al}$, densidade, porosidade total e capacidade de aeração no solo, e a abundância e a biomassa das ervas. Concluiu-se que quando as aléias foram combinadas de forma a permitir aplicação de baixa e alta qualidade de resíduos, houve diminuição na ocorrência e agressividade das ervas daninhas, ao mesmo tempo em que foi melhorada a fertilidade do solo.
\end{abstract}

Palavras-chave: atributos físicos e químicos do solo; controle de ervas daninhas; plantio direto; plantas leguminosas.

\begin{abstract}
In humid tropical land-use systems weed diversity and aggressiveness are extremely high, posing serious limitations to no-tillage agriculture. This paper investigates the effects of combining low- and high-quality organic residues on weed abundance and biomass and selected soil quality indicators. For this purpose, a field experiment was installed in January 2002 on-station at Maranhao State University, comprising four legume species: Leucaena leucocephala (Lam.) De Wit., Cajanus cajan (L.) Millsp, Clitoria fairchildiana R.A.Howard and Acacia mangium Willd., resulting in the following treatments in a completely randomized block design with 4 replications: L.leucocephala + C.cajan; A.mangium + C.cajan; C.fairchildiana + L.leucocephala; L.leucocephala + A.mangium and control (no legumes). Sampling was conducted in 2005 and 2007. We determined weed abundance and biomass, and $\mathrm{N}, \mathrm{P}, \mathrm{K}, \mathrm{Ca}$, lignin e polyphenol contents of the residues. In the topsoil we determined $\mathrm{pH}$, the contents of organic matter, $\mathrm{P}, \mathrm{K}, \mathrm{Ca}, \mathrm{Mg}$, and $\mathrm{H}+\mathrm{Al}$, and soil density, total porosity and aeration capacity. We conclude that aggressiveness of weeds can be reduced and at the same time soil fertility can be improved with alley-cropping systems which contain the combination of both high- and low-quality residue producing plants.
\end{abstract}

Key-words: soil physical and chemical attributes; weed control; no-tillage; legumes.

\footnotetext{
'Engenheiro Agrônomo, Doutor em Agronomia, Professor do Programa de Pós-Graduação em Agroecologia da Universidade Estadual do Maranhão (UEMA), Caixa Postal 3004, 65054-970, São Luís, MA - Brasil. E-mail: egmoura@elo.com.br. Autor para correspondência.

${ }^{2}$ Engenheira Agrônoma, Doutora em Agronomia, Professora do Centro de Ciências Agrárias e Ambientais, Universidade Federal do Maranhão, Chapadinha, MA - Brasil. E-mail: alanaaguiar@elo.com.br

${ }^{3}$ Engenheiro Agrônomo, Doutor em Agronomia, Professor do Departamento de Química e Biologia, Universidade Estadual do Maranhão, São Luís, MA - Brasil. E-mail: aferrazjr@cecen.uema.br.

${ }^{4}$ Engenheiro Agrônomo, Aluno do Curso de Mestrado em Agroecologia, Bolsista da Fundação de Amparo à Pesquisa e ao Desenvolvimento Científico e Tecnológico do Maranhão (FAPEMA), São Luís, MA - Brasil. E-mail: webmaster@uema.br

${ }^{5}$ Engenheiro Agrônomo, Aluno do Curso de Mestrado em Agroecologia, Bolsista CAPES/FAPEMA, São Luís, MA - Brasil. E-mail: thiagronomo@yahoo.com.br

${ }^{6}$ Engenheiro Agrônomo, Aluno do Curso de Mestrado em Agroecologia, Bolsista CAPES/FAPEMA, São Luís, MA - Brasil. E-mail: jrufra@hotmail.com

${ }^{7}$ Geógrafo, Doutor em Agroecologia, Professor Visitante do Programa de Pós-Graduação em Agroecologia da Universidade Estadual do Maranhão, São Luís, MA - Brasil. E-mail: cgehring@uema.br.
} 


\section{INTRODUÇÃO}

No trópico úmido, devido às altas temperaturas e as chuvas intensas, os efeitos do preparo das terras com arado ou grade podem ser negativos, e por este motivo o uso do plantio direto na palha tem sido recomendado como prática importante para a sustentabilidade dos agroecossistemas (Moura et al., 2008). Nos agrossistemas desta região a agressividade e a variedade de ervas daninhas, são muito grandes. Em um sistema de aléias com a leguminosa arbórea Clitoria fairchildiana, em fase de implantação na pré-Amazônia brasileira, Araújo et al. (2008), identificaram 42 espécies de ervas, sendo mais da metade delas com freqüência e densidades importantes do ponto de vista da competição com a cultura do arroz. Nestas condições, a incidência de ervas daninhas se constitui em uma das principais limitações à adoção do sistema de plantio direto, e aumenta a importância da integração de práticas de controles alternativos para viabilizar a agricultura familiar na região tropical, dentro dos princípios das tecnologias limpas (Jordan, 2004).

Segundo Maclean et al. (2003), o sistema de cultivo em aléias favorece três estratégias para o controle de ervas: o sombreamento da área durante a estação de crescimento das árvores pode reduzir a abundância das espécies sensíveis à sombra; com o corte e a aplicação dos ramos das árvores ao solo, a cobertura morta previne a germinação das sementes; e a decomposição dos resíduos aplicados ao longo do tempo melhora os indicadores de fertilidade do solo alterando a composição das ervas e a habilidade da cultura para competir contra elas.

O sombreamento das árvores usadas no sistema em aléias pode diminuir a densidade e a biomassa das ervas em níveis diferentes, dependendo da espécie utilizada. Em trabalho conduzido por Anoka et al. (1991) tanto a gliricídia quanto a leucena foram importantes na supressão do Imperata cylindrica, por sombreamento, mas a gliricídia foi $16 \%$ mais eficiente na redução da densidade daquela gramínea.

O impacto da cobertura sobre a densidade das ervas está relacionado à sua presença física e aos efeitos biológicos de produtos alelopáticos derivados da decomposição dos resíduos (Weston, 2005). Os mais conhecidos destes efeitos, são atribuídos a compostos produzidos por algumas leguminosas, como a leucena, que afetam a germinação e o crescimento das ervas (John \& Narwal, 2003; Yeung et al., 2002; Williams \& Hoagland, 2007). A presença física da cobertura atua como barreira à penetração da luz e à emergência das sementes e será tão mais eficiente quanto melhor for sua atuação nesses dois processos, como reportaram Masiunas et al. (2003) que avaliaram o uso de espumas biológicas de diferentes cores na cultura do tomateiro. Segundo Johnson et al. (2004) o efeito físico da cobertura varia com a época de aplicação, sendo mais eficiente quando aplicado mais cedo.

Modificações nos níveis de fertilidade do solo alteram o número de espécies, a biomassa das ervas daninhas e a relação entre as comunidades de folhas largas/folhas estreitas, que aumenta com a melhoria da fertilidade do solo (Maclean et al., 2003). Em trabalho de Major et al. (2005), conduzido na Amazônia brasileira, a incidência de ervas se correlacionou positivamente com os teores de cálcio, magnésio, potássio, fósforo e com o pH do solo. Melhores correlações foram encontradas entre a densidade das ervas e os teores de cálcio e o $\mathrm{pH}$, o que indica que o aumento delas pode se relacionar mais estreitamente com a saturação por bases.

O sistema de cultivo em aléias tem se mostrado capaz de contribuir para a sustentabilidade dos sistemas agrícolas tropicais por sua capacidade de manter um estoque adequado de cátions na zona de crescimento das raízes (Vanlauwe et al., 2005). Para os solos da região tropical úmida trabalhos como os de Leite et al. (2008) e Moura et al. (2008) recomendam o plantio direto em palhas de leguminosas em aléias como sistema adequado para o manejo sustentável dos agroecossistemas, por sua capacidade de proteção do solo, de reciclagem de nutrientes, e por aumentar a produtividade das culturas. $O$ aproveitamento das vantagens do sistema, entretanto, deve considerar também sua eficiência no controle das ervas daninhas o que pressupõe a escolha das espécies de árvores que incorporem, além da melhoria dos atributos de fertilidade do solo, os efeitos de sombreamento, de supressão física, e de produtos alelopáticos sobre a comunidade de ervas.

Este trabalho foi conduzido com o objetivo de avaliar o efeito de resíduos de baixa e alta qualidade, derivados de diferentes combinações de aléias, sobre a densidade e a biomassa de ervas daninhas e sobre a fertilidade de um Argissolo do trópico úmido.

\section{MATERIALE MÉTODOS}

O experimento foi instalado em janeiro de 2002 na Universidade Estadual do Maranhão, campus de São Luís, Maranhão, localizado a $2^{\circ} 30^{\prime}$ latitude sul e $44^{\circ} 18^{\prime}$ longitude oeste. O clima da região é equatorial quente e úmido, com duas estações bem definidas: uma estação chuvosa que se estende de janeiro a junho com precipitação média de $2.100 \mathrm{~mm}^{2} \mathrm{ano}^{-1}$ e uma estação seca, com déficit hídrico acentuado de julho a dezembro. O solo da área experimental foi classificado como Argissolo Vermelho-Amarelo Distrófico arênico (EMBRAPA, 2006), com as seguintes características granulométricas: areia grossa $=260 \mathrm{~g} \mathrm{~kg}^{-1}$; areia fina $=560 \mathrm{~g} \mathrm{~kg}^{-1}$; silte $=80 \mathrm{~g} \mathrm{~kg}^{-1} \mathrm{e}$ argila $=100 \mathrm{~g}$ $\mathrm{kg}^{-1}$.

Com base nos resultados da análise do solo foi feita em janeiro de 2002, uma aplicação superficial, de cal hidratada, na dosagem de $1 \mathrm{Mg}$ 
$\mathrm{ha}^{-1}$, correspondente a 390 e $130 \mathrm{~kg} \mathrm{ha}^{-1}$ de Ca e $\mathrm{Mg}$ respectivamente.

$\mathrm{Na}$ implantação das aléias foram usadas quatro espécies de leguminosas, duas de alta qualidade de resíduos - Leucaena leucocephala (Lam.) De Wit.) (leucena) e Cajanus cajan (L.) Millsp) (guandu), e duas de baixa qualidade de resíduos Clitoria fairchildiana R.A.Howard (sombreiro) e Acacia mangium Willd. (acácia). Para a definição da qualidade foram utilizados os critérios de Young (1997) para o qual os resíduos de alta qualidade tem altos teores de $\mathrm{N}$ e baixos teores de lignina $\mathrm{e}$ polifenóis, e o contrário para os de baixa qualidade. As espécies foram semeadas em fileiras de $4 \mathrm{~m}$ de largura de forma que cada parcela recebeu dois tipos de resíduos, resultante da combinação de duas leguminosas, formando os seguintes tratamentos: Sombreiro + Guandu ( $S+G)$; Leucena + Guandu $(L+G)$; Acácia + Guandu (A+G); Sombreiro + Leucena $(S+L)$; Leucena + Acácia $(L+A)$ e Testemunha, sem leguminosas. Utilizou-se o delineamento experimental em blocos ao acaso com quatro repetições. As leguminosas foram espaçadas de $0,5 \mathrm{~m}$ entre plantas, em parcelas de $21 \times 4 \mathrm{~m}$. Na área entre as leguminosas foram semeadas quatro linhas de milho no espaçamento de $1 \mathrm{~m} \times 0,25 \mathrm{~m}$, adubadas com $250 \mathrm{~kg} \mathrm{ha}^{-1}$ da fórmula $\mathrm{N}-\mathrm{P}_{2} \mathrm{O}_{5}-\mathrm{K}_{2} \mathrm{O}$
$10-25-15+0,05 \%$ Zn. Foram também aplicados 30 $\mathrm{kg} \mathrm{ha}^{-1}$ de $\mathrm{N}$ na forma de sulfato de amônio, como adubação de cobertura, quando do surgimento do quarto par de folhas do milho. O crescimento insatisfatório das leguminosas no primeiro ano não permitiu o corte em 2003 e, portanto, as podas foram realizadas em janeiro de 2004, 2005, 2006 e 2007, após a germinação da cultura de milho, à altura de aproximadamente $50 \mathrm{~cm}$. As quantidades de biomassa produzidas pelas leguminosas foram igualmente distribuídas entre todas as parcelas de cada tratamento.

As espécies acácia e sombreiro produziram maior quantidade de resíduos em todos os cortes. A partir do terceiro corte houve uma diminuição pronunciada na produção do guandu, mas nos tratamentos em que esta leguminosa foi combinada com acácia, o rápido crescimento desta última compensou o menor desenvolvimento do guandu. Estas diferenças na produtividade das espécies ocasionaram uma grande variação entre os tratamentos em relação à quantidade de resíduo aplicada (Tabela 1). Nos dois últimos cortes o tratamento acácia + leucena recebeu três vezes mais resíduo que o da leucena + guandu que foram as leguminosas menos produtivas.

TABELA 1 - Biomassa seca aplicada por tratamento, em $\mathrm{Mg} \mathrm{ha}^{-1}$, aos dois e aos quatro anos.

\begin{tabular}{ccc}
\hline Tratamentos & $2004 / 2005$ & $2006 / 2007$ \\
\hline Sombreiro+Guandu & 15,70 & 13,98 \\
Leucena+Guandu & 12,84 & 12,52 \\
Acácia+Guandu & 21,29 & 32,73 \\
Sombreiro+Leucena & 14,48 & 21,80 \\
Leucena+Acácia & 20,07 & 37,45 \\
\hline
\end{tabular}

Devido às diferenças nas quantidades de material aplicadas aos tratamentos e em função das variações da qualidade dos resíduos, as quantidades de componentes e nutrientes adicionados nos tratamentos foram também muito diferentes (Tabela 2). Devem ser ressaltadas principalmente as diferenças na qualidade dos resíduos representada pelas quantidades de polifenol, lignina, $\mathrm{N}$ e $\mathrm{Ca}$, que foram adicionados em muito maior quantidade nos tratamentos acácia + leucena, do que no leucena + guandu e sombreiro + guandu. Em virtude do aumento da produtividade do sombreiro, leucena e acácia ao longo do tempo, estas diferenças foram maiores nos dois últimos cortes.

As análises químicas do solo, realizadas em amostras coletadas em 2007, nas profundidades de $0-5$ e 5-10 cm, foram as seguintes: $\mathrm{pH}$ em $\mathrm{CaCl}_{2}$, matéria orgânica, $\mathrm{P}, \mathrm{K}^{+}, \mathrm{Ca}^{2+}, \mathrm{Mg}^{2+}, \mathrm{H}+\mathrm{Al}$, capacidade de troca catiônica a pH 7 (CTC), soma de bases (SB) e saturação por bases (V) segundo metodologia do Instituto Agronômico de Campinas (2001).

As amostras para avaliação dos atributos físicos do solo foram coletadas em anéis volumétricos com capacidade de $100 \mathrm{~cm}^{3}$, em agosto de 2006, com três determinações por parcela, na profundidade de 7 a $14 \mathrm{~cm}$. Nestas amostras foram determinadas a densidade do solo (Ds); a porosidade total $(\mathrm{Pt})$ e a capacidade de aeração (Car) segundo Thomasson (1978).

A coleta das ervas espontâneas foi realizada em duas épocas com intervalo de dois anos, a primeira época depois do segundo corte (fevereiro de 2005) e a segunda época após o quarto corte (fevereiro de 2007). Foram realizadas três determinações ao acaso, por parcela segundo Hyvönen et al. (2003) e Jakelaitis et al. (2003). A identificação das ervas foi realizada de acordo com Kissmann \& Groth (1992; 1995) e Kissmann (1997). Após a identificação as ervas foram contadas e secas em estufa a $70^{\circ} \mathrm{C}$, até massa constante (Marenco \& Santos, 1999).

Os dados foram analisados estatisticamente com auxílio do programa Statistica 6.0 (Statsoft, 2007). Os resultados obtidos foram submetidos à análise de variância, com comparação de médias pelo teste de Tukey a $5 \%$ de probabilidade. 
MOURA, E.G. et al. Incidência de ervas daninhas e atributos do solo...

TABELA 2 - Quantidade de produtos orgânicos e nutrientes adicionados por tratamento, via resíduos vegetais, nos dois primeiros e dois últimos cortes.

\begin{tabular}{|c|c|c|c|c|c|c|c|c|}
\hline \multirow{2}{*}{ Tratamentos } & \multicolumn{8}{|c|}{$2004 / 2005$} \\
\hline & $\mathrm{C} / \mathrm{N}^{1}$ & Polifenol $^{2}$ & Lignina $^{2}$ & $\mathrm{~N}^{1}$ & $\mathrm{P}^{1}$ & $\mathrm{~K}^{1}$ & $\mathrm{Ca}^{1}$ & $\mathrm{Mg}^{1}$ \\
\hline & \multicolumn{3}{|c|}{--- Mg ha $^{-1}$} & \multicolumn{5}{|c|}{ - } \\
\hline Sombreiro+Guandu & 18 & 162,83 & 171,55 & 232,83 & 19,45 & 68,80 & 142,47 & 27,73 \\
\hline Leucena+Guandu & 20 & 115,74 & 76,55 & 269,32 & 21,10 & 75,23 & 120,92 & 19,46 \\
\hline Acácia+Guandu & 18 & 316,32 & 223,71 & 296,61 & 19,65 & 87,28 & 250,86 & 27,17 \\
\hline Sombreiro+Leucena & 22 & 257,17 & 213,58 & 430,26 & 31,25 & 123,47 & 228,84 & 42,19 \\
\hline \multirow[t]{2}{*}{ Leucena+Acácia } & 20 & 409,74 & 260,11 & 494,06 & 30,51 & 141,95 & 337,23 & 41,63 \\
\hline & \multicolumn{8}{|c|}{$2006 / 2007$} \\
\hline Sombreiro+Guandu & 20 & 243,27 & 242,04 & 321,50 & 14,8 & 95,26 & 200,45 & 39,69 \\
\hline Leucena+Guandu & 20 & 211,77 & 130,10 & 484,65 & 12,54 & 131,07 & 209,78 & 34,11 \\
\hline Acácia+Guandu & 19 & 683,14 & 468,99 & 610,71 & 10,8 & 176,76 & 526,30 & 56,58 \\
\hline Sombreiro+Leucena & 25 & 388,35 & 252,88 & 698,83 & 20,28 & 211,71 & 385,63 & 70,24 \\
\hline Leucena+Acácia & 21 & 764,13 & 484,76 & 924,72 & 16,23 & 293,21 & 711,49 & 86,62 \\
\hline
\end{tabular}

\section{RESULTADOS E DISCUSSÃO}

\section{Atributos químicos e físicos do solo}

$\mathrm{Na}$ camada de 0 a $5 \mathrm{~cm}$ todas as combinações de resíduos afetaram a soma de bases (SB) com intensidade variável mais significativas em relação à testemunha, o que refletiu positivamente na saturação por bases (V) (Tabela $3)$. Diferenças nos teores de cálcio foram os responsáveis por estas variações, uma vez que não houve mudança significativa nos níveis de potássio e magnésio. Estes resultados do valor $V$ podem ser considerados importantes não apenas por sua significância estatística, mas principalmente pelo efeito agronômico que poderá advir da mudança de nível crítico de baixo para médio, segundo o critério de Ribeiro et al. (1999).

$\mathrm{Na}$ camada de 5 a $10 \mathrm{~cm}$ os tratamentos leucena + acácia e leucena + guandu foram os únicos que produziram incrementos significativos nos valores de $\mathrm{Ca}^{2+}$, SB e V. Considerando ambas as camadas amostradas, estas foram então as combinações de espécies mais eficientes para sustentar condições favoráveis ao crescimento das culturas e das ervas. Esta eficiência segundo Vanlauwe et al. (2005) está relacionada a dois fatores: primeiro ao padrão de enraizamento destas espécies leguminosas que permitem uma maior absorção dos nutrientes pelas raízes e sua concentração nos resíduos, (caso da acácia e da leucena) e segundo a maior taxa de desmobilização dos nutrientes que derivam da decomposição (caso da leucena e do guandu). A capacidade do sistema retornar parte do cálcio para superfície, aliada à sua mobilidade no solo, pode levar a uma redistribuição deste elemento no perfil ao longo do tempo, melhorando as condições químicas para o crescimento das raízes das culturas e das ervas daninhas (Dechert et al., 2005). Para o magnésio, cuja grande mobilidade nos solos arenosos torna mais difícil a manutenção de seus níveis adequados no perfil, nenhum dos tratamentos diferiram da testemunha em relação à sua concentração na superfície, portanto foram bem menores as eficiências dos sistemas para recuperação deste elemento (Kolahchi \& Jalali, 2007). Também para o potássio, foi significativamente nula a contribuição dos resíduos para o aumento de concentrações deste nutriente no solo. Neste caso, como as ligações do potássio com as argilas e matéria orgânica são relativamente fracas, a desorção e substituição deste elemento pelo cálcio podem ter causado sua depleção no perfil como observaram Jalali \& Rowell (2003). No caso do P as pequenas variações dos teores deste elemento entre os tratamentos, mesmo quando estatisticamente significativas, podem ser consideradas de pouco significado agronômico, conquanto não foram suficientes para a mudança de nível crítico desse elemento no solo. 
MOURA, E.G. et al. Incidência de ervas daninhas e atributos do solo...

TABELA 3 - Atributos químicos do solo, nas profundidades de 0-5 e 5-10 cm, sob diferentes tipos de cobertura após seis anos do estabelecimento das aléias, em São Luís, MA, 2007.

\begin{tabular}{|c|c|c|c|c|c|c|c|c|c|c|}
\hline \multirow{2}{*}{ Tratamentos } & $\mathrm{pH}$ & $\mathrm{MO}$ & $P$ & $\mathrm{~K}^{+}$ & $\mathrm{Ca}^{2+}$ & $\mathrm{Mg}^{2+}$ & $\mathrm{H}+\mathrm{Al}$ & SB & CTC & $\mathrm{V}$ \\
\hline & $\mathrm{CaCl}_{2}$ & $\mathrm{~g} \mathrm{dm}^{3}$ & $\mathrm{mg} \mathrm{dm}^{3}$ & \multicolumn{6}{|c|}{ - } & $\%$ \\
\hline & \multicolumn{10}{|c|}{ 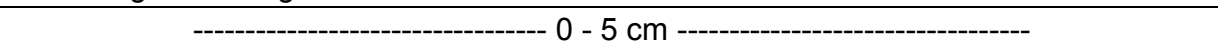 } \\
\hline Sombreiro + Guandu & 4,5 & 22 & 11 & 0,4 & $19 \mathrm{a}$ & 3 & 26 & $22,4 \mathrm{a}$ & $48,4 \mathrm{a}$ & $46 \mathrm{a}$ \\
\hline Leucena+Guandu & 4,4 & 18 & 11 & 0,4 & $16 \mathrm{a}$ & 2 & 23 & $18,4 a b$ & $41,4 \mathrm{a}$ & $45 a$ \\
\hline Acácia+Guandu & 4,7 & 20 & 9 & 0,4 & $11 \mathrm{~b}$ & 2 & 20 & $13,4 b$ & $33,4 \mathrm{~b}$ & $40 \mathrm{a}$ \\
\hline Sombreiro+Leucena & 4,5 & 21 & 12 & 0,4 & $11 \mathrm{~b}$ & 3 & 24 & $14,4 \mathrm{~b}$ & $38,4 \mathrm{~b}$ & $38 a$ \\
\hline Leucena+Acácia & 4,6 & 20 & 10 & 0,4 & $18 a$ & 3 & 22 & $21,4 \mathrm{a}$ & $43,4 \mathrm{a}$ & $50 a$ \\
\hline Testemunha & 4,3 & 17 & 14 & 0,4 & $6 \mathrm{c}$ & 1 & 28 & $7,4 \mathrm{c}$ & $35,4 \mathrm{~b}$ & $21 \mathrm{~b}$ \\
\hline $\mathrm{F}$ & $1,41^{\text {ns }}$ & $0,48^{\text {ns }}$ & $0,67^{\text {ns }}$ & $0,23^{\mathrm{ns}}$ & * & $2,10^{\mathrm{ns}}$ & $1,44^{\mathrm{ns}}$ & * & * & * \\
\hline CV (\%) & 6 & 26 & 41 & 36 & 15 & 45 & 19 & 15 & 12 & 11 \\
\hline \multirow[t]{2}{*}{ DMS } & 0,52 & 6,10 & 5,20 & - & 4,72 & 2,38 & 8,44 & 4,85 & 7,50 & 12,59 \\
\hline & \multicolumn{10}{|c|}{ 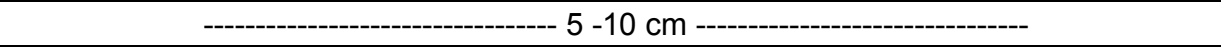 } \\
\hline Sombreiro + Guandu & 4,3 & 14 & $12 \mathrm{a}$ & 0,3 & $7 \mathrm{~b}$ & 2 & 23 & $9,3 \mathrm{~b}$ & 32 & $29,1 \mathrm{~b}$ \\
\hline Leucena+Guandu & 4,5 & 14 & $10 a b$ & 0,3 & $13 \mathrm{a}$ & 2 & 24 & 15,3 a & 39 & $39,2 \mathrm{a}$ \\
\hline Acácia+Guandu & 4,4 & 14 & $8 \mathrm{~b}$ & 0,5 & $7 \mathrm{~b}$ & 2 & 22 & $9,5 b$ & 31 & $30,6 \mathrm{~b}$ \\
\hline Sombreiro+Leucena & 4,3 & 14 & $10 a b$ & 0,3 & $6 \mathrm{~b}$ & 2 & 26 & $8,3 \mathrm{~b}$ & 34 & $24,4 \mathrm{~b}$ \\
\hline Leucena+Acácia & 4,5 & 13 & $14 \mathrm{a}$ & 0,3 & $14 \mathrm{a}$ & 2 & 22 & 16,3 a & 38 & 42,9 a \\
\hline Testemunha & 4,1 & 13 & $10 a b$ & 0,5 & $6 \mathrm{~b}$ & 1 & 27 & $7,5 \mathrm{~b}$ & 35 & $21,4 \mathrm{~b}$ \\
\hline $\mathrm{F}$ & $1,01^{\text {ns }}$ & $0,10^{\text {ns }}$ & * & $0,77^{\mathrm{ns}}$ & * & $0,64^{\mathrm{ns}}$ & $0,57^{\mathrm{ns}}$ & * & $0,81^{\mathrm{ns}}$ & * \\
\hline CV (\%) & 6 & 17 & 13 & 63 & 22 & 40 & 22 & 18 & 12 & 25 \\
\hline DMS & 0,45 & 1,33 & 2,30 & 0,29 & 1,69 & 1,23 & 5,48 & 2,51 & 8,68 & 9,00 \\
\hline
\end{tabular}

Médias seguidas pela mesma letra na mesma coluna, não diferem estatisticamente pelo teste de Tukey a $5 \%$.

$\mathrm{NS}=$ não significativo; * = significativo; $\mathrm{MO}=$ matéria orgânica; $\mathrm{SB}=$ soma de bases; $\mathrm{CTC}=$ capacidade de troca catiônica; $\mathrm{V}=$ saturação por bases.

Entre os indicadores físicos analisados, as alterações na capacidade de aeração do solo podem ser consideradas mais importantes do que as diferenças entre a testemunha e os demais tratamentos encontradas para a densidade e porosidade total, que podem apresentar valores ótimos, não iguais para diferentes solos (Håkansson \& Lipiec, 2000; Dexter, 2004) (Tabela 4). Por outro lado, no trópico úmido a disponibilidade de $\mathrm{O}_{2}$ pode ser crítica diminuindo o crescimento das plantas nos períodos de maior precipitação como relatam Moura et al. (2008). Em solos arenosos a ausência, ou a destruição dos agregados, provocado pelo impacto da chuva em solos descobertos, aumenta a compacidade do solo e obriga a água e o ar a circularem nos mesmos espaços, o que segundo Currie (1962) e Gliñsk \& Stepniewski (1983), diminui o coeficiente de difusão do $\mathrm{O}_{2}$ no solo, e afeta a respiração das raízes, a absorção de água, a disponibilidade de $\mathrm{N}$ e a capacidade fotossintética das plantas sensíveis ao déficit de $\mathrm{O}_{2}$ na zona radicular.

TABELA 4 - Densidade do solo, capacidade de aeração e porosidade total, na profundidade de 7 a $14 \mathrm{~cm}$, sob diferentes tipos de coberturas após seis anos do estabelecimento das aléias, em São Luís, MA, 2007.

\begin{tabular}{cccc}
\hline Tratamentos & Densidade do solo & Capacidade de aeração & Porosidade total \\
\hline & $----\mathrm{Mg} \mathrm{m}^{-3}-----$ & $-----\mathrm{m}^{3} \mathrm{~m}^{-3}$--------- \\
\cline { 2 - 4 } Sombreiro + Guandu & $1,30 \mathrm{a}$ & $0,16 \mathrm{a}$ & $0,50 \mathrm{a}$ \\
Leucena + Guandu & $1,32 \mathrm{a}$ & $0,17 \mathrm{a}$ & $0,50 \mathrm{a}$ \\
Acácia + Guandu & $1,30 \mathrm{a}$ & $0,16 \mathrm{a}$ & $0,50 \mathrm{a}$ \\
Sombreiro + Leucena & $1,32 \mathrm{a}$ & $0,16 \mathrm{a}$ & $0,48 \mathrm{ab}$ \\
Leucena + Acácia & $1,32 \mathrm{a}$ & $0,16 \mathrm{a}$ & $0,49 \mathrm{ab}$ \\
Testemunha & $1,40 \mathrm{~b}$ & $0,10 \mathrm{~b}$ & $0,46 \mathrm{~b}$ \\
\hline CV (\%) & 2 & 10 & 2 \\
DMS & 0,06 & 0,05 & 0,03
\end{tabular}




\section{Abundância e biomassa das ervas daninhas}

Os tratamentos com participação da acácia se destacaram como os de maior efeito sobre a abundância de ervas, observando-se, nas duas épocas de amostragem, diferenças significativas entre estes tratamentos e a testemunha. No primeiro ano da amostragem somente o tratamento sombreiro + guandu não contribuiu para a diminuição da abundância de ervas (Tabela 5). A não ser na combinação com acácia, no segundo ano os tratamentos com guandu exerceram menor efeito na abundância de ervas por causa da queda da produção desta leguminosa. Vale ressaltar que, em todas as parcelas com acácia foi muito menor a abundância em relação aos demais tratamentos.

TABELA 5 - Abundância e biomassa seca de ervas daninhas após três (2005) e cinco (2007) anos, após o estabelecimento das aléias, em São Luís, MA.

\begin{tabular}{ccccc}
\hline & \multicolumn{2}{c}{ Abundância $\left(\right.$ número $\left.\mathrm{m}^{-2}\right)$} & \multicolumn{2}{c}{ Biomassa $\left(\mathrm{g} \mathrm{m}^{-2}\right)$} \\
\cline { 2 - 5 } & 2005 & 2007 & 2005 & 2007 \\
\hline Sombreiro + Guandu & $75 \mathrm{a}$ & $100 \mathrm{a}$ & $40 \mathrm{a}$ & $105 \mathrm{~b}$ \\
Leucena + Guandu & $28 \mathrm{~b}$ & $70 \mathrm{ab}$ & $24 \mathrm{~b}$ & $165 \mathrm{a}$ \\
Acácia + Guandu & $13 \mathrm{~b}$ & $10 \mathrm{c}$ & $14 \mathrm{~b}$ & $10 \mathrm{c}$ \\
Sombreiro + Leucena & $25 \mathrm{~b}$ & $60 \mathrm{~b}$ & $15 \mathrm{~b}$ & $75 \mathrm{~b}$ \\
Leucena + Acácia & $20 \mathrm{~b}$ & $25 \mathrm{c}$ & $30 \mathrm{~b}$ & $11 \mathrm{c}$ \\
Testemunha & $70 \mathrm{a}$ & $65 \mathrm{ab}$ & $55 \mathrm{a}$ & $90 \mathrm{~b}$ \\
\hline DMS & 16,74 & 37,82 & 15,50 & 30,61 \\
\hline
\end{tabular}

Médias seguidas da mesma letra na coluna não diferem estatisticamente pelo teste de Tukey a $5 \%$.

As diferenças na biomassa de ervas daninhas na segunda amostragem (2007) confirmaram a maior eficiência da acácia na diminuição do potencial competitivo das ervas (Tabela 5), por seu efeito supressivo derivado tanto da quantidade quanto da durabilidade de seus resíduos. No tratamento com resíduos de alta qualidade $(L+G)$, a melhoria na fertilidade do solo, combinada com a ausência de cobertura duradoura, resultou em biomassa de ervas maior do que em todos os tratamentos, inclusive na testemunha, o que ressalta a importância do uso de espécies diferentes que favoreça ao mesmo tempo a reciclagem eficiente de nutrientes e a cobertura do solo, para diminuir a competitividade das ervas. De um modo geral estes resultados confirmam a hipótese de Maclean et al. (2003), em relação ao efeito do sombreamento e da presença física dos resíduos no sistema em aléias, e também concordam com os dados de Major et al. (2005) sobre a influência da saturação por bases na biomassa de ervas. Nos tratamentos sem acácia com menor produção de biomassa (Tabela 1), ou melhor qualidade de resíduos, foi maior a biomassa das ervas na segunda amostragem (2007), pois estas leguminosas têm maior efeito sobre a fertilidade do que sobre a cobertura do solo. Por outro lado, a aplicação dos resíduos de baixa qualidade teve efeito cumulativo sobre o potencial de competição pelas plantas daninhas, porque as diferenças na biomassa entre os vários tratamentos foram mais evidentes na segunda amostragem.

Quando as comunidades de ervas foram separadas, percebeu-se que a abundância de dicotiledôneas não foi afetada pelos tratamentos em 2005. O crescimento dessas ervas foi estimulado pela qualidade dos resíduos, pois a sua biomassa na segunda amostragem (2007) foi maior nos tratamentos com leucena e guandu do que na testemunha, a não ser quando combinados com acácia (Tabela 6). Na segunda amostragem os tratamentos com acácia diminuíram, de maneira significativa, tanto a abundância quanto a biomassa das monocotiledôneas. Por outro lado, houve um aumento significativo, em relação a todos os outros tratamentos, tanto na abundância quanto na biomassa das ervas monocotiledôneas no tratamento leucena + guandu, o que ressalta o caráter oportunista desse grupo de ervas daninhas que se beneficiaram da melhor fertilidade e da menor cobertura do solo neste tratamento. A biomassa das monocotiledôneas foi afetada por todos os tratamentos com sombreiro e acácia o que significa que este grupo se mostrou mais sensível aos resíduos de baixa qualidade que diminuíram o seu potencial de competição.

As diferenças encontradas neste experimento podem ser interpretadas com base nos dados de qualidade e quantidade dos resíduos mostrados nas Tabelas 1 e 2. De maneira geral as ervas foram menos competitivas nas parcelas com maior quantidade de resíduos de menor qualidade $(A+G$ e $A+L)$, o que reforça a importância da escolha da espécie de leguminosa para o manejo dos agrossistemas da região. Estes resultados indicam também que a opção por espécies de menor acúmulo de biomassa e maior qualidade de resíduo pode melhorar os indicadores de fertilidade, mas terá efeito nulo ou negativo sobre o controle das ervas. Por outro lado, fica evidenciada, para efeito do controle das ervas daninhas, a importância da permanência dos resíduos na superfície o que depende de sua taxa de decomposição, ou de seu índice de qualidade, como descrito por Tian et al. (1995). 
MOURA, E.G. et al. Incidência de ervas daninhas e atributos do solo...

TABELA 6 - Abundância de dicotiledôneas e monocotiledôneas sobre a biomassa de dicotiledôneas e monocotiledôneas aos três (2005) e cinco (2007) anos após o estabelecimento das aléias em São Luís (MA).

\begin{tabular}{|c|c|c|c|c|}
\hline \multirow{3}{*}{ Tratamentos } & \multicolumn{4}{|c|}{ Abundância (número $\mathrm{m}^{-2}$ ) } \\
\hline & \multicolumn{2}{|c|}{ Monocotiledôneas } & \multicolumn{2}{|c|}{ Dicotiledôneas } \\
\hline & 2005 & 2007 & 2005 & 2007 \\
\hline Sombreiro + Guandu & $10 \mathrm{~b}$ & $15 b$ & $30 \mathrm{a}$ & $65 \mathrm{a}$ \\
\hline Leucena + Guandu & $4 \mathrm{~b}$ & $52 a$ & $27 \mathrm{a}$ & $30 \mathrm{bc}$ \\
\hline Acácia + Guandu & $11 \mathrm{~b}$ & $5 \mathrm{c}$ & $15 \mathrm{a}$ & $10 \mathrm{~d}$ \\
\hline Sombreiro + Leucena & $4 \mathrm{~b}$ & $11 \mathrm{~b}$ & $20 \mathrm{a}$ & $40 \mathrm{~b}$ \\
\hline Leucena + Acácia & $4 \mathrm{~b}$ & $5 c$ & $12 \mathrm{a}$ & $20 \mathrm{~cd}$ \\
\hline Testemunha & $20 \mathrm{a}$ & $30 \mathrm{a}$ & $20 a$ & $15 d$ \\
\hline \multirow[t]{4}{*}{ DMS } & 8,13 & 5,37 & 19,60 & 10,51 \\
\hline & \multicolumn{4}{|c|}{ Biomassa $\left(\mathrm{g} \mathrm{m}^{-2}\right)$} \\
\hline & \multicolumn{2}{|c|}{ Monocotiledôneas } & \multicolumn{2}{|c|}{ Dicotiledôneas } \\
\hline & 2005 & 2007 & 2005 & 2007 \\
\hline Sombreiro + Guandu & $5 \mathrm{~b}$ & $7 \mathrm{c}$ & $25 \mathrm{a}$ & $70 \mathrm{a}$ \\
\hline Leucena + Guandu & $1 \mathrm{~b}$ & $90 \mathrm{a}$ & $12 b$ & $40 \mathrm{~b}$ \\
\hline Acácia + Guandu & $3 \mathrm{~b}$ & $1 \mathrm{c}$ & $8 \mathrm{~b}$ & $11 \mathrm{c}$ \\
\hline Sombreiro + Leucena & $1 \mathrm{~b}$ & $2 c$ & $12 \mathrm{~b}$ & $65 a$ \\
\hline Leucena + Acácia & $1 \mathrm{~b}$ & $1 \mathrm{c}$ & $5 b$ & $11 \mathrm{c}$ \\
\hline Testemunha & $25 \mathrm{a}$ & $27 \mathrm{~b}$ & $13 b$ & $25 \mathrm{bc}$ \\
\hline DMS & 3,2 & 7,3 & 8,9 & 16,0 \\
\hline
\end{tabular}

Médias seguidas da mesma letra na coluna não diferem estatisticamente pelo teste de Tukey a $5 \%$.

\section{CONCLUSÕES}

1) No sistema de cultivo em aléias a combinação de resíduos de baixa e alta qualidade, aplicada na mesma área diminui a incidência e a competitividade das ervas daninhas, mesmo com a vantagem de aumentar a fertilidade do solo na camada de 0 a $10 \mathrm{~cm}$.

2) Os resíduos de alta qualidade como os de leucena e guandu, se utilizados sozinhos, tornam - sistema menos adequado para o manejo agroecológico, por não apresentar efeitos supressivos significativos e aumentar a fertilidade do solo e como conseqüência o crescimento das ervas daninhas.

3) As principais modificações resultantes da aplicação da mistura de resíduos de alta e baixa qualidade são os aumentos da capacidade de aeração do solo e da saturação por bases, resultante da reciclagem do cálcio, ambos de grande importância para o manejo dos agrossistemas do trópico úmido.

\section{AGRADECIMENTO E CONFLITOS DE INTERESSES}

Ao Conselho Nacional de Desenvolvimento Científico e Tecnológico (CNPq) pelo apoio financeiro na implantação do projeto de pesquisa (Processo $\left.n^{\circ} 551366 / 2001-0\right)$.

O presente trabalho não apresenta conflitos de interesses que sejam do conhecimento dos autores.

\section{REFERÊNCIAS}

1. ANDERSON, J. D.; INGRAM, J. S. I. Tropical soil biology and fertility: a handbook of methods. 2. ed. Wallingford: CAB International, 1996. $171 \mathrm{p}$.

2. ANOKA, U. A.; AKOBUNDU, I. O.; OKONKWO, S. N. C. Effects of Gliricidia sepium (Jacq.) Steud and Leucaena leucocephala (Lam.) de Wit on growth and development of Imperata cylindrical (L.) Raeuschel. Agroforestry Systems, v. 16, n. 1, p. 1-12, 1991.

3. ARAÚJO, A. S. F.; SANTOS, V. B.; MONTEIRO, R. T. R. Responses of soil microbial biomass and activity for practices of organic and conventional farming systems in Piauí state, Brazil. European Journal of Soil Biology, v. 44, n. 2, p. 225-230, 2008.

4. CURRIE, J. A. Gaseous diffusion in the aeration of aggregated soils. Soil Science, v. 92, p. 40-45, 1962.

5. DECHERT, G.; VELDKAMP, E.; BRUMME, R. Are partial nutrient balances suitable to evaluate nutrient sustainability of land use systems? Results from a case study in Central Sulawesi, Indonesia. Nutrient Cycling in Agroecosystems, v. 72, n. 3 , p. $201-212,2005$ 
MOURA, E.G. et al. Incidência de ervas daninhas e atributos do solo...

6. DEXTER, A. R. Soil physical quality. Part III: unsaturated hydraulic conductivity and general conclusions about Stheory. Geoderma, v. 120, n. 3/4, p.227-239, 2004

7. EMPRESA BRASILEIRA DE PESQUISA AGROPECUÁRIA (EMBRAPA). Sistema Brasileiro de Classificação de Solos. 2. ed. Rio de Janeiro: Embrapa Solos, 2006. 306 p.

8. GLIÑSKI, J.; STEPNIEWSKI, W. Soil aeration and its role for plants. Boca Raton: CRC Press, 1983. 229 p.

9. HÅKANSSON, I.; LIPIEC, J. A review of the usefulness of relative bulk density values in studies of soil stucture and compaction. Soil \& Tillage Research, v. 53, n. 2, p. 71-85, 2000.

10. HYVÖNEN, T.; KETOJA, E.; SALONEN, J. Changes in the abundance of weeds in spring cereal fields in Finland. Weed Research, v. 43, n. 5, p. 348-356, 2003.

11. INSTITUTO AGRONOMICO DE CAMPINAS. Análise química para avaliação da fertilidade de solos tropicais. RAIJ, B. VAN. et al. (Ed.). Campinas: IAC, 2001. 285 p.

12. JAKELAITIS, A. et al. Dinâmica populacional de plantas daninhas sob diferentes sistemas de manejo nas culturas de milho e feijão. Planta Daninha, v. 21, n. 1, p. 71-79, 2003.

13. JALALI, M.; ROWELL, D. L. The role of calcite and gypsum in the leaching of potassium in a sandy soil. Experimental Agriculture, v. 39, n. 4, p. 379-394, 2003.

14. JOHN, J.; NARWAL, S. S. Allelopathy plants. Leucaena leucocephala (Lam.) de Wit. Allelopathy Journal, v. 12, n. 1, p. 13-36, 2003

15. JOHNSON, J. M.; HOUGH-GOLDSTEIN, J. A.; VANGESSEL, M. J. Effects of straw mulch on pest insects, predators, and weeds in watermelons and potatoes. Environmental Entomology, v. 33, n. 6, p. 1632-1643, 2004

16. JORDAN, C. F. Organic farming and agroforestry: alleycropping for mulch production for organic farms of southeastern United States. Agroforestry Systems, v. 61/62, n. 1/3, p. 79-90, 2004.

17. KISSMANN, K. G.; GROTH, D. Plantas infestantes e nocivas. Tomo II, São Paulo: Basf S.A., 1992. 798 p.

18. KISSMANN, K. G.; GROTH, D. Plantas infestantes e nocivas. Tomo III, São Paulo: Basf S.A., 1995. 683 p.

19. KISSMANN, K. G. Plantas infestantes e nocivas. Tomo I, 2. ed. São Paulo: Basf, 1997. 824 p.

20. KOLAHCHI, Z.; JALALI, M. Effect of water quality on the leaching of potassium from sandy soil. Journal of Arid Environments, v. 68, n. 4, p. 624-639, 2007

21. LEITE, A. A. L. et al. Comportamento de dois genótipos de milho cultivados em sistema de aléias pré-estabelecidos com diferentes leguminosas arbóreas. Bragantia, v. 67, n. 4, p. 817-825, 2008.

22. MACLEAN, R. H. et al. Impact of Gliricidia spectabilis hedgerows on weeds and insect pests of upland rice. Agriculture, Ecosystems and Environment, v. 94, p. 275-288, 2003.

23. MAJOR, J. et al. Weed composition and cover after three years of soil fertility management in the central Brazilian Amazon: compost, fertilizer, manure and charcoal applications. Weed Biology and Management, v. 5, p. 69-76, 2005.

24. MARENCO, R. A.; SANTOS, A. M. B. Crop rotation reduces weed competition and increases chlorophyll concentration and yield of rice. Pesquisa Agropecuária Brasileira, v. 34, n. 10, p. 1881-1887, 1999.

25. MASIUNAS, J. et al. A foam mulching systems to control weeds in tomatoes and sweet basil. Horttechnology, v. 13 , n. 2, p. 324-328, 2003

26. MOURA, E. G.; ALBUQUERQUE, J. M.; AGUIAR, A. C. F. Growth and productivity of corn as affected by mulching and tillage in alley cropping systems. Scientia Agricola, v. 65, n. 2, p. 204-208, 2008.

27. RIBEIRO, A. C.; GUIMARÃES, P. T. G.; ALVAREZ, V. H. V. (Ed.). Recomendações para o uso de corretivos e fertilizantes em Minas Gerais. 5. aprox. Viçosa: Universidade Federal de Viçosa, 1999. 359 p.

28. STATSOFT. Electronic Statistics Program. Tulsa: StatSoft, 2007. 1 CD-ROM.

29. TEDESCO, M. J. Extração simultânea de N, P, K, Ca e Mg em tecido de planta por digestão por $\mathrm{H}_{2} \mathrm{O}_{2}-\mathrm{H}_{2} \mathrm{SO}_{4}$. Porto Alegre: UFRGS, 1982. Apostila. (Informativo Interno).

30. THOMASSON, A. J. Towards an objective classification of soil structure. Journal Soil Science, v. 29, p. 38-46, 1978

31. TIAN, G., BRUSSAARD, L., KANG, B. T. An index for assessing the quality of plant residues and evaluating their effects on soil and crop in the (sub-) humid tropics. Applied Soil Ecology, v. 2, p. 25-32, 1995.

32. VANLAUWE, B. et al. Long-term integrated soil fertility management in South-western Nigeria: crop performance and impact on the soil fertility status. Plant and Soil, v. 273, p. 337-354, 2005.

33. WESTON, L. A. History and current trends in the use of allelopathy for weed management. Horttechnology, v. 15, n. 3, p. 529-534, 2005.

34. WILLIAMS, R. D.; HOAGLAND, R. E. Phytotoxicity of mimosine and albizziine on seed germination and seedling growth of crops and weeds. Allelopathy Journal, v. 19, n. 2, p. 423-430, 2007.

35. YEUNG, P. K. K.; WONG, F. T. W.; WONG, J. T. Y. Mimosine, the allelochemical from the leguminous tree Leucaena leucocephala, selectively enhances cell proliferation in Dinoflagellates. Applied and Environmental Microbiology, v. 68 , n. 10 , p. $5160-5163,2002$.

36. YOUNG, A. Agroforestry for soil management. London: Cab International, 1997. 307 p.

Recebido em 18/02/2008 Aceito em 15/09/2008 